\title{
Stray dogs in Nepal have high prevalence of vector-borne pathogens: a molecular survey
}

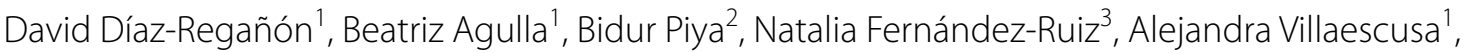 \\ Mercedes García-Sancho ${ }^{1}$, Fernando Rodríguez-Franco ${ }^{1}$ and Ángel Sainz ${ }^{1 *}$
}

\begin{abstract}
Background: Population of stray dogs is significant in large cities of Nepal, such as Kathmandu. Most of stray dogs suffer a lack of basic health care. Considering the clinical relevance, the broad distribution and the lack of information of canine vector borne diseases (CVBD) in Nepal, the aim of this study was to evaluate the prevalence of different vector-borne pathogens (VBP) in stray dogs living in the metropolitan area of Kathmandu, and to assess different traits as possible risk factors.
\end{abstract}

Methods: A total of 70 canine blood samples from stray dogs attended at the Kathmandu Animal Treatment Centre during August 2017 were collected on filter paper (Flinders Technology Associates (FTA) cards). Data regarding signalment, clinical signs and epidemiological characteristics were recorded for each animal. Real-time polymerase chain reaction assays were performed for Leishmania spp., Ehrlichia spp./Anaplasma spp., Babesia spp./Theileria spp. and Hepatozoon canis.

Results: The overall prevalence detected was 31.43\% for Hepatozoon canis, 31.43\% for Anaplasma platys, 27.14\% for Ehrlichia canis, $18.57 \%$ for Leishmania donovani species complex, $12.86 \%$ for isolates corresponding to Theileria spp., $12.86 \%$ for Babesia vogeli and $2.86 \%$ for B. gibsoni. A total of $81.43 \%$ of the dogs were positive to at least one of the VBP tested. Co-infections were detected in $41.43 \%$ of the dogs. Dogs positive to any of the VBP tested, and particularly to E. canis, were older than those that were negative.

Conclusions: To our knowledge, this is the first molecular detection of VBP in stray dogs from Kathmandu, Nepal. The high prevalence of VBP detected highlights the need to implement a surveillance programme and control strategies for these CVBD in the population of stray dogs in this area.

Keywords: Nepal, Canine vector borne disease, PCR, FTA card, Leishmania, Ehrlichia, Anaplasma, Babesia, Theileria, Hepatozoon

\section{Background}

Populations of stray dogs are significant in large cities of Nepal, such as Kathmandu [1]. However, data on the demographics of stray dogs in Nepal remains unknown [2]. Most of free-roaming dogs suffer from malnutrition,

\footnotetext{
*Correspondence: angelehr@vet.ucm.es

${ }^{1}$ Department of Animal Medicine and Surgery, College of Veterinary Medicine, Complutense University of Madrid, Avda. Puerta de Hierro s/n 28040 Madrid, Spain

Full list of author information is available at the end of the article
}

diseases and lack of basic health care (deworming, antiparasitic treatments or vaccination) [2].

While the status of rabies in these dog populations is a major issue for the Public Health in Nepal [3], information about the prevalence of other zoonotic diseases $[2,4$, $5]$ and specifically, canine vector borne diseases (CVBD) is really scarce. A molecular evaluation of different vector-borne pathogens (VBP) is lacking.

Kathmandu Valley is located in the warm temperate area of the country, where the climate is fairly temperate, 
and appropiate for the presence of different vectors of relevance for the dog population such as sand flies and hard ticks.

The aim of this study was to evaluate the prevalence of different VBP in stray dogs living in the metropolitan area of Kathmandu, Nepal, and to assess different traits as possible risk factors. Taking into account the clinical relevance, the broad distribution and the lack of information in dogs from Nepal, the pathogens evaluated in this study were Leishmania spp. Ehrlichia spp./Anaplasma spp., Babesia spp./Theileria spp. and Hepatozoon canis.

\section{Methods}

Canine blood samples from stray dogs attending the Kathmandu Animal Treatment Centre during August 2017 were collected for further molecular analyses. Different data regarding signalment, clinical signs, and epidemiological characteristics were recorded for each animal. We aimed to perform real-time polymerase chain reaction assays for Leishmania spp., Ehrlichia spp./Anaplasma spp., Babesia spp./Theileria spp. and Hepatozoon canis.

\section{Animals and samples, and data collection}

A total of 70 blood samples from stray dogs attended at the Kathmandu Animal Treatment Centre (KAT Centre) during August 2017 were collected from the core of the metropolitan area of Kathmandu, Nepal. Stray dogs were opportunistically sampled when they were brought into the clinic for medical treatment or for neutering procedures as a part of animal birth control (ABC) programmes. Dogs with and without clinical signs were included in this study. Dog blood samples obtained by venipuncture were spotted on Whatman FTA $^{\circledR}$ (Flinders Technology Associates) classic cards (Whatman International Ltd, Maidstone, UK) for further molecular analyses. To avoid cross-contamination, these samples were stored in separate plastic bags that included storage desiccant packets to ensure that FTA cards remained dry during transport and storage. Samples were kept at room temperature during the entire campaign and were later stored at $-20{ }^{\circ} \mathrm{C}$ until DNA extraction. Data regarding signalment, clinical signs and presence of ectoparasites were recorded for each animal.

\section{DNA extraction and quality assessment}

DNA was extracted using SpeedTools Tissue DNA extraction commercial kit (Biotools, B\&M Laboratories, S.A., Madrid, Spain) according to the manufacturer's instructions. All DNA samples were stored at $-20{ }^{\circ} \mathrm{C}$ until use. The extraction yield (quality and quantity of the extracted DNA) was assessed by means of spectrophotometry (Nanodrop ${ }^{\mathrm{TM}}$; Thermo Fisher Scientific, Waltham, USA). The eukaryotic $18 S$ ribosomal ribonucleic acid (18S rRNA) (Thermo Fisher Scientific) was used as an internal reference of canine genomic DNA to ensure proper extraction (presence/absence of DNA inhibition factors).

\section{Real-time PCR assays}

Real-time PCR assays were used to target selected species of VBP, including Babesia/Theileria species, Ehrlichia/ Anaplasma species, Hepatozoon canis and Leishmania donovani complex species as previously described $[6,7]$.

Real-time PCR reactions were conducted in a $20 \mu \mathrm{l}$ reaction mixture containing PowerUp SYBR Green master mix (Thermo Fisher Scientific, Carlsbad, CA, USA), specific primers (Table 1 ) and $4 \mu \mathrm{l}$ of $1 / 5$ diluted DNA. The thermal cycling profile was $50{ }^{\circ} \mathrm{C}$ for 2 min and 95 ${ }^{\circ} \mathrm{C}$ for 2 min, followed by 40 cycles at $95^{\circ} \mathrm{C}$ for $3 \mathrm{~s}$ and 60 ${ }^{\circ} \mathrm{C}$ for $30 \mathrm{~s}$ and a dissociation curve added at the end of the run to asses PCR-specificity. Commercial DNA and water were used with each amplification run as a positive and negative PCR controls, respectively. PositivePCR amplicons were directly sequenced to characterize pathogens at the species level using the same primers. Subsequent sequencing was performed in all the positive samples, using the Big Dye ${ }^{\circledR}$ Terminator version 3.1 Cycle Sequencing kit (Thermo Fisher Scientific, Carlsbad, CA, USA) following the manufacturer's instructions.

Table 1 PCR primers used for detection of selected vector-borne pathogens: Ehrlichia spp., Anaplasma spp., Hepatozoon canis, Babesia spp., Theileria spp. and Leishmania spp. in dogs from Kathmandu, Nepal

\begin{tabular}{|c|c|c|c|c|}
\hline Species & Target gene & Forward primer $\left(5^{\prime}-3^{\prime}\right)$ & Reverse primer $\left(5^{\prime}-3^{\prime}\right)$ & References \\
\hline Ehrlichia spp.; Anaplasma spp. & 165 rRNA & GCAAGCYTAACACATGCAAGTCG & GGATTATACAGTATTACCCAYCATTTCTARTG & {$[6]$} \\
\hline Hepatozoon canis & 18S rRNA & CTTACCGTGGCAGTGACGGT & ATTGTTATTTCTTGTTACTACCTCTCTCAAAC & \\
\hline Piroplasmida (Babesia/Theileria spp.) & & GACGATCAGATACCGTCGTAGTCC & CAGAACCCAAAGACTTTGATTTCTCTC & \\
\hline Leishmania spp. & $\begin{array}{l}\text { Kinetoplast } \\
\text { minicircle } \\
\text { DNA }\end{array}$ & AACTTTTTCTGGTCCTCCGGGTAG & ACCCCCAGTTTCCCGCC & {$[7]$} \\
\hline
\end{tabular}

Abbreviation: rRNA ribosomal ribonucleic acid 
Sequences obtained were compared with those deposited on GenBank using the Basic Local Alignment Search Tool (BLAST).

\section{Statistical analysis}

The results were statistically analysed using the software SAS, version 9.4 (SAS Institute, Cary, NC, USA). Statistical associations between VBP and epidemiological data recorded for each stray dog were analysed using Chi-square test or Fisher's exact test, where appropriate, and Student's t-test to evaluate mean age with positive or negative effects for different vector-borne pathogens. In order to exclude possible confounding factors, complementary logistic regression analysis with backward elimination was performed with those variables that showed a statistical association. The level of statistical significance was established at $P<0.05$.

\section{Results}

\section{Dog population description}

Samples were collected from 24 different locations of the metropolitan area of Kathmandu, Nepal: Balaju $(n=2)$; Bansbari $(n=2)$; Budanilkantha $(n=25)$; Chapali Bhadrakali $(n=3)$; Dhapasi $(n=1)$; Dhumbarahi $(n=2)$; Ring Road Dhungedara, Banasthali $(n=3)$; Durbar Marg $(n$ $=1)$, Gaurighat $(n=1)$; Golfutar $(n=3)$; Hattigauda $(n$ $=1)$; Jamal $(n=3)$; Kalimati $(n=2)$; Lazimpat $(n=2)$; Lyangfang $(n=1)$; Maharajgunj $(n=3)$; Manamaiju $(n=$ $1)$; Mandikhatar $(n=3)$; Nayabazar $(n=2)$; New Road ( $n$ $=1)$; Shovabhagbati $(n=1)$; Swoyambhu $(n=4)$; Thulo Bharyang $(n=2)$; and Tokha $(n=1)$.

Among the 70 stray dogs included in the study, 29 (41.43\%; 95\% CI: 29.9-53\%) were males and 41 (58.57\%; 95\% CI: $47.0-70.1 \%)$ were females. Most of the dogs were local mongrels that could not be associated with any breed (97.14\%; 95\% CI: 93.2-100\%) except for two Japanese Spitz dogs. Age of the dogs ranged from one month to 14 years, with a mean age of $3.78 \pm 2.93$ yearsold. A total of 29/70 (41.43\%; 95\% CI: $29.9-53.0 \%)$ were neutered.

Considering the clinical status, a total of 46/70 dogs (65.71\%; 95\% CI: 54.6-75.8\%) presented clinical signs, and 24/70 (34.39\%; 95\% CI: 23.2-45.4\%) remained apparently healthy. Regarding physical examination, only two dogs were dehydrated, and two presented lymphadenopathies. When considering mucous membrane examination, pallor was detected in eight dogs (11.43\%; 95\% CI: $4.0-18.9 \%$ ), and capillary refill time (CRT) was longer than two seconds in three dogs $(4.29 \%$; $95 \%$ CI: $0-9.0 \%)$. Thirty four out of 70 of the dogs (48.57\%; $95 \%$ CI: 36.9-60.3\%) presented underweight (BCS $\leq 4 / 9)$. On the other hand, only 13 dogs (18.57\%, 95\% CI: 9.5-27.7\%) presented overweight $(\mathrm{BCS}=6 / 9 ; n=6$ and $\mathrm{BCS}=7 / 9$; $n=7)$.

When assessing ectoparasites presence, hard ticks (family Ixodidae) were detected on 42 out of 70 dogs (60\%; 95\% CI: 48.5-71.5\%). No soft ticks (family Argasidae) were detected. Furthermore, 31 out of 70 (44.29\%; 95\% CI: $32.6-55.9 \%$ ) had flea infestation. A total of 24 out of 70 (34.28\%; 95\% CI: 23.2-45.4\%) carried both ectoparasites. On the other hand, skin lesions compatible with mange were present in 23 dogs (32.86\%; 95\% CI: 21.943.9\%). Concurrent ticks, fleas and mange-suspected infestation were presented in eight dogs $(11.42 \%$; $95 \% \mathrm{CI}$ : 4.0-18.9\%). All data regarding signalment, clinical, and environmental variables are shown in Table 2.

\section{PCR amplification and sequencing results}

Hepatozoon canis was detected in 22 (31.43\%; 95\% CI: 20.6-42.2\%) of the samples using a species-specific PCR. A total of 41 dogs (58.57\%; 95\% CI: $47.0-70.1 \%$ ) were positive to Anaplasma/Ehrlichia spp., with 22 PCR sequences (31.43\%; 95\% CI: 20.6-42.3\%) corresponding to Anaplasma platys, and 19 (27.14\%; 95\% CI: 16.7-37.6\%) to Ehrlichia canis. Leishmania donovani complex species were detected in 13 dogs (18.57\%; 95\% CI: 9.5-27.7\%).

A total of 20 dogs (28.57\%; 95\% CI: $18.0-39.2 \%)$ were positive to Babesia spp./Theileria spp. These values correspond to a total rate of $15.71 \%$ (11/70; CI: 7.2-24.2\%) of Babesia spp. further determined as $12.86 \%$ (9/70; 95\% CI:5.0-20.7\%) for B. vogeli and $2.86 \%(2 / 70 ; 95 \% \mathrm{CI}$ : 0-6.8\%) for B. gibsoni, and $12.86 \%$ (9/70; $95 \%$ CI: $5.0-$ $20.7 \%)$ to an unidentified species that matched with several isolates of Theileria spp. (T. sinensis, T. luwenshuni or T. annulata among others) but unrelated to Babesia vulpes (formerly known as Theileria annae). The prevalence of CVBD agents according to different variables, including signalment, clinical findings, and environmental data are shown in Table 2.

When considering co-infections, $40 \%$ (28/70; 95\% CI: 28.5-51.1\%) of dogs were positive to single VBP, and 41.43\% (29/70; 95\% CI: 29.9-53.0\%) presented co-infections. Of these, nine dogs (12.86\%; 95\% CI: 5.0-20.7\%) were positive to three different VBP (Table 3). Considering single infections, $E$. canis was the most detected VBP (9/70; $12.86 \%$; 95\% CI: 5.0-20.7\%) and B. vogeli was found in only two dogs $(2.86 \%, 95 \%$ CI: 0-6.8\%). Babesia gibsoni was always found in combination with other VBP infection. The most common co-infections detected in the study were $H$. canis + E. canis $(7 / 70 ; 10 \% ; 95 \% \mathrm{CI}$ : 3.0-17.0\%) and H. canis + A. platys $(6 / 70 ; 8.57 \%$; $95 \%$ CI: $2.0-15.1 \%)$. Data regarding single infections and coinfections are shown in Table 3. 
Table 2 Comparison of prevalence of selected VBP in association with different epidemiological data recorded in the study

\begin{tabular}{|c|c|c|c|c|c|c|c|c|c|}
\hline \multirow[t]{3}{*}{ Variable } & \multirow{3}{*}{$\begin{array}{l}\text { Total no. of dogs } \\
(\%) \\
70\end{array}$} & \multicolumn{8}{|c|}{ Number of VBP positive dogs (\%) } \\
\hline & & \multirow{2}{*}{$\begin{array}{l}\text { Any VBP } \\
-\quad 57(81.43)\end{array}$} & \multirow{2}{*}{$\begin{array}{l}\text { H. canis } \\
22(31.43)\end{array}$} & \multirow{2}{*}{$\begin{array}{l}\text { A. platys } \\
22(31.43)\end{array}$} & \multirow{2}{*}{$\begin{array}{l}\text { E. canis } \\
19(27.14)\end{array}$} & \multirow{2}{*}{$\begin{array}{l}\text { Leishmania spp. } \\
13(18.57)\end{array}$} & \multirow{2}{*}{$\begin{array}{l}\text { Theileria spp. } \\
9(12.86)\end{array}$} & \multirow{2}{*}{$\begin{array}{l}\text { B. vogeli } \\
9(12.86)\end{array}$} & \multirow{2}{*}{$\begin{array}{l}\text { B. gibsoni } \\
2(2.86)\end{array}$} \\
\hline & & & & & & & & & \\
\hline Average age & 70 & & & & & & & & \\
\hline Positive & na & $4.09 \pm 3.30^{*}$ & $3.96 \pm 2.57$ & $3.77 \pm 2.76$ & $5.16 \pm 3.39^{*}$ & $4.40 \pm 2.69$ & $3.51 \pm 3.00$ & $2.42 \pm 2.05$ & $1.75 \pm 0.35$ \\
\hline Negative & na & $2.40 \pm 1.09$ & $3.7 \pm 3.10$ & $3.79 \pm 3.03$ & $3.27 \pm 2.59$ & $3.64 \pm 2.98$ & $3.82 \pm 2.94$ & $3.98 \pm 3.00$ & $3.84 \pm 2.95$ \\
\hline Sex & 70 & & & & & & & & \\
\hline Male & $29(41.43)$ & $25(86.21)$ & $12(41.38)$ & $9(31.03)$ & $11(37.93)$ & $3(10.34)$ & $4(13.79)$ & $2(6.90)$ & $1(3.45)$ \\
\hline Female & $41(58.57)$ & $32(78.05)$ & $10(24.39)$ & $13(31.71)$ & $8(19.51)$ & $10(24.39)$ & $5(12.20)$ & $7(17.07)$ & $1(2.44)$ \\
\hline Age & 70 & & & & & & & & \\
\hline $\begin{array}{l}\text { Puppy (<1-year- } \\
\text { old) }\end{array}$ & $8(11.43)$ & $5(62.50)$ & $1(12.50)$ & $2(25.00)$ & $0(0)$ & $1(12.50)$ & $3(37.50)^{*}$ & $1(12.50)$ & $0(0)$ \\
\hline $\begin{array}{l}\text { Adult (1-5-year- } \\
\text { old) }\end{array}$ & $42(60.00)$ & $34(80.95)$ & $15(35.71)$ & $13(30.95)$ & $12(28.57)$ & $6(14.29)$ & $3(7.14)$ & $7(16.67)$ & $2(4.76)$ \\
\hline $\begin{array}{l}\text { Mature adult } \\
\qquad(>5 \text {-year-old })\end{array}$ & $20(28.57)$ & $18(90.00)$ & $6(30.00)$ & $7(35.00)$ & $7(35)$ & $6(30.00)$ & $3(15.00)$ & $1(5.00)$ & $0(0)$ \\
\hline Spay/neutered & 70 & & & & & & & & \\
\hline Yes & $29(41.43)$ & $26(89.66)$ & $10(34.48)$ & $8(27.59)$ & $12(41.38)^{*}$ & $7(24.14)$ & $3(10.34)$ & $2(6.90)$ & $1(3.45)$ \\
\hline No & $41(58.57)$ & $31(75.61)$ & $12(29.27)$ & $14(34.15)$ & $7(17.07)$ & $6(14.63)$ & $6(14.63)$ & $7(17.07)$ & $1(2.44)$ \\
\hline $\mathrm{BCS}$ & 70 & & & & & & & & \\
\hline $\begin{array}{l}\text { Underweight } \\
\quad(1-<5)\end{array}$ & $34(48.57)$ & $26(76.47)$ & $10(29.41)$ & $8(23.53)$ & $10(29.41)$ & $6(17.65)$ & $3(8.82)$ & $6(17.65)$ & $0(0)$ \\
\hline Normal weight (5) & $23(32.86)$ & $18(78.26)$ & $9(39.13)$ & $9(39.13)$ & $5(21.74)$ & $3(13.04)$ & $3(13.04)$ & $2(8.70)$ & $2(8.70)$ \\
\hline $\begin{array}{l}\text { Overweight } \\
\quad(>5-9)\end{array}$ & $13(18.57)$ & $13(100)$ & $3(23.08)$ & $5(38.46)$ & $4(30.77)$ & $4(30.77)$ & $3(23.08)$ & $1(7.69)$ & $0(0)$ \\
\hline Clinical signs & 70 & & & & & & & & \\
\hline Yes & $46(65.71)$ & $39(84.71)$ & $15(32.61)$ & $14(30.43)$ & $15(32.61)$ & $8(17.39)$ & $6(13.04)$ & $5(10.87)$ & $1(2.17)$ \\
\hline No & $24(34.39)$ & $18(75.00)$ & $7(29.17)$ & $8(33.33)$ & $4(16.67)$ & $5(20.83)$ & $3(12.50)$ & $4(16.67)$ & $1(4.17)$ \\
\hline Mucous membrane & 70 & & & & & & & & \\
\hline Normal & $62(88.57)$ & $51(82.26)$ & $21(33.87)$ & $19(30.65)$ & $17(27.42)$ & $12(19.35)$ & $7(11.29)$ & $8(12.90)$ & $2(3.23)$ \\
\hline Pallor & $8(11.43)$ & $6(75.00)$ & $1(12.50)$ & $3(37.50)$ & $2(25.00)$ & $1(12.50)$ & $2(25.00)$ & $1(12.50)$ & $0(0)$ \\
\hline CRT & 70 & & & & & & & & \\
\hline Normal CRT & $67(95.71)$ & $54(80.60)$ & $21(31.34)$ & $21(31.34)$ & $18(26.87)$ & $12(17.91)$ & $9(13.43)$ & $9(13.43)$ & $2(2.99)$ \\
\hline Longer than $2 \mathrm{sec}$ & $3(4.29)$ & $3(100)$ & $1(33.33)$ & $1(33.33)$ & 1 (33.33) & $1(33.33)$ & $0(0)$ & $0(0)$ & $0(0)$ \\
\hline Dehydration & 70 & & & & & & & & \\
\hline Yes & $2(2.86)$ & $2(100)$ & $0(0)$ & $0(0)$ & $1(50.00)$ & $1(50.00)$ & $0(0)$ & $0(0)$ & $0(0)$ \\
\hline No & $68(97.14)$ & $55(80.88)$ & $22(32.35)$ & $22(32.35)$ & $18(26.47)$ & $12(17.65)$ & $9(13.24)$ & $9(13.24)$ & $2(2.94)$ \\
\hline $\begin{array}{l}\text { Lymphadenopa- } \\
\text { thies }\end{array}$ & 70 & & & & & & & & \\
\hline Yes & $2(2.86)$ & $2(100)$ & $0(0)$ & $1(50.00)$ & $1(50.00)$ & $0(0)$ & $1(50.00)$ & $0(0)$ & $0(0)$ \\
\hline No & $68(97.14)$ & $55(80.88)$ & $22(32.35)$ & $21(30.88)$ & $18(26.47)$ & $13(19.12)$ & $8(11.76)$ & $9(13.24)$ & $2(2.94)$ \\
\hline Tick infestation & 70 & & & & & & & & \\
\hline Yes & $42(60.00)$ & $37(88.10)$ & $15(35.71)$ & $14(33.33)$ & $13(30.95)$ & $5(11.90)$ & $7(16.67)$ & $4(9.52)$ & $2(4.76)$ \\
\hline No & $28(40.00)$ & $20(71.43)$ & $7(25.00)$ & $8(28.57)$ & $6(21.43)$ & $8(28.57)$ & $2(7.14)$ & $5(17.86)$ & $0(0)$ \\
\hline Flea infestation & 70 & & & & & & & & \\
\hline Yes & $31(44.29)$ & $25(80.65)$ & $7(22.58)$ & 13 (41.94) & $6(19.35)$ & $5(16.13)$ & $4(12.90)$ & $5(16.13)$ & $0(0)$ \\
\hline No & $39(55.71)$ & $32(82.05)$ & 15 (38.46) & $9(23.08)$ & $13(33.33)$ & $8(20.51)$ & $5(12.82)$ & $4(10.26)$ & $2(5.13)$ \\
\hline Mange & 70 & & & & & & & & \\
\hline Yes & $23(32.86)$ & $19(82.61)$ & $9(39.13)$ & $7(30.43)$ & $7(30.43)$ & $4(17.39)$ & $4(17.39)$ & $4(17.39)$ & $0(0)$ \\
\hline No & $47(67.14)$ & $38(80.85)$ & $13(27.66)$ & 15 (31.91) & $12(25.53)$ & $9(19.15)$ & $5(10.64)$ & $5(10.64)$ & $2(4.26)$ \\
\hline
\end{tabular}

Abbreviations: VBP, vector-borne pathogens; H. canis, Hepatozoon canis; A. platys, Anaplasma platys; E. canis, Ehrlichia canis; Leishmania spp., Leishmania donovani species complex; B. canis vogeli, Babesia canis vogeli; B. gibsoni, Babesia gibsoni; BCS, body condition score; CRT, capillary refill time; na, not applicable ${ }^{*} P<0.05$ 
Table 3 Single infections and co-infections for the VBP studied in stray dogs from Kathmandu, Nepal

\begin{tabular}{|c|c|c|c|}
\hline \multicolumn{2}{|c|}{ Vector-borne pathogen } & No. of PCR-positive dogs (\%) & $95 \% \mathrm{Cl}$ \\
\hline \multicolumn{2}{|l|}{ Single infections } & $28(40.00)$ & $28.5-51.5$ \\
\hline \multicolumn{2}{|l|}{ Ehrlichia canis } & $9(12.86)$ & $5.0-20.7$ \\
\hline \multicolumn{2}{|l|}{ Anaplasma platys } & $7(10.00)$ & $3.0-17.0$ \\
\hline \multicolumn{2}{|l|}{ Hepatozoon canis } & $5(7.14)$ & $1.1-13.2$ \\
\hline \multicolumn{2}{|c|}{ Leishmania donovani species complex } & $4(5.71)$ & $0.3-11.2$ \\
\hline \multicolumn{2}{|l|}{ Babesia vogeli } & $2(2.86)$ & $0-6.8$ \\
\hline \multicolumn{2}{|l|}{ Theileria spp. ${ }^{a}$} & $1(1.43)$ & $0-4.2$ \\
\hline \multicolumn{2}{|l|}{ Co-infections } & $29(41.43)$ & $29.9-53.0$ \\
\hline \multirow[t]{10}{*}{ Co-infection (2 VBP) } & E. canis + H. canis & $4(5.71)$ & $0.3-11.2$ \\
\hline & A. platys + H. canis & $4(5.71)$ & $0.3-11.2$ \\
\hline & A. platys + Theileria spp. & $3(4.28)$ & $0-9.0$ \\
\hline & B. gibsoni + A. platys & $2(2.86)$ & $0-6.8$ \\
\hline & L. donovani complex + E. canis & $2(2.86)$ & $0-6.8$ \\
\hline & L. donovani complex + H. canis & $1(1.43)$ & $0-4.2$ \\
\hline & L. donovani complex + A. platys & $1(1.43)$ & $0-4.2$ \\
\hline & B. vogeli + L. donovani complex & $1(1.43)$ & $0-4.2$ \\
\hline & Theileria spp. + H. canis & $1(1.43)$ & $0-4.2$ \\
\hline & A. platys + B. vogeli & $1(1.43)$ & $0-4.2$ \\
\hline \multirow[t]{7}{*}{ Co-infection (3 VBP) } & Theileria spp. + A. platys + H. canis & $2(2.86)$ & $0-6.8$ \\
\hline & B. vogeli + E. canis + H. canis & $2(2.86)$ & $0-6.8$ \\
\hline & B. vogeli + E. canis + L. donovani complex & $1(1.43)$ & $0-4.2$ \\
\hline & B. gibsoni + E. canis + H. canis & $1(1.43)$ & $0-4.2$ \\
\hline & B. vogeli + A. platys + L. donovani complex & $1(1.43)$ & $0-4.2$ \\
\hline & Theileria spp. + H. canis + L. donovani complex & $1(1.43)$ & $0-4.2$ \\
\hline & Theileria spp. + A. platys + L. donovani complex & $1(1.43)$ & $0-4.2$ \\
\hline \multicolumn{2}{|l|}{ Total } & $57(81.43)$ & $72.3-90.5$ \\
\hline
\end{tabular}

${ }^{a}$ Theileria spp.: sequences compatible with Theileria spp. (sequences were not further confirmed by amplification of the long 185 sequence)

Abbreviation: $\mathrm{Cl}$, confidence interval

\section{Epidemiological and clinical data}

We did not detect statistically significant associations between the presence of VBP studied and sex $\left(\chi^{2}=0.74\right.$, $d f=1, P=0.38)$ or BCS $\left(\chi^{2}=3.67, d f=2, P=0.16\right)$. Considering any VBP infection, positive dogs were older $(4.09 \pm 3.3$ years-old $)$ than negative dogs $(2.4 \pm 1.09$ years-old) (Student's t-test, $t=1.92, P=0.05)$. Furthermore, there was no relationship between the presence of clinical signs and the infection with any VBP $\left(x^{2}=0.99\right.$, $d f=1, P=0.31$ ) (Table 2).

The co-infection with more than one VBP in the same animal was not associated with any of the variables evaluated. Additionally, tick-infestation detected during physical exam of dogs was not statistically associated with any of the tick-vector borne agents studied (Hepatozoon canis $\left(\chi^{2}=0.89, d f=1, P=0.34\right)$, A. platys $\left(\chi^{2}=0.18, d f=1\right.$, $P=0.67)$, E. canis $\left(\chi^{2}=0.77, d f=1, P=0.38\right)$, or any Babesia/Theileria spp. $\left(\chi^{2}=1.16, d f=1, P=0.28\right)$. This only suggests the unreliability of tick detection by clinicians in the moment of hospital application as suggestive of tick-borne agents.

Ehrlichia canis was the only pathogen displaying a statistical association with dog-derived traits. When looking to $E$. canis infection specifically, it was observed that dogs with a positive PCR result were also older (5.16 \pm 3.39 years-old $)$ than negative dogs $(3.27 \pm 2.59$ yearsold) (Student's t-test, $t=2.49, P=0.0153$ ). On the other hand, neutered status was also associated with PCR-positive result for $E$. canis $\left(\chi^{2}=5.07, d f=1, P=0.024\right)$. However, complementary logistic regression analysis with backward elimination was performed including those variables in a model and demonstrated that these associations were not statistically significant (neutered status $(P$ $=0.09$; OR: 2.68 ; 95\% CI: $0.85-8.43)$ and age $(P=0.067$; OR: 1.2 ; 95\% CI: 0.99-1.47). 


\section{Discussion}

To our knowledge, this study addressed the first molecular survey of VBP in stray dogs from the metropolitan area of Kathmandu, Nepal, and the first report of $H$. canis infection in dogs from this region. A high prevalence of VBP was detected in this study using real-time PCR technique. The results presented here support the scarce findings of previous studies that detected Leishmania spp. in dogs in some regions of Nepal [8]. Babesia sp., Ehrlichia sp. and Anaplasma sp. have also been recently detected by microscopy in blood smears from hyperthermic owned dogs in Kathmandu Valley [9, 10].

Previous studies in the region have found an overall prevalence of haemoparasites between 10-17.14\% in dogs considered under risk based on clinical signs like fever or hyperthermic dogs, or those carrying tickinfestation [9]. However, our study shows a higher prevalence of selected VBP (81.43\%). This could be explained because previous studies were performed on owned dogs (that usually receive the adequate veterinarian care). Most of the stray dogs involved in our study were highly exposed to tick and sand fly bites. In addition, differences in the techniques employed for the detection of these pathogens could explain, at least partially, the differences in the prevalences detected. It has been previously established that real time-PCR is considerably more sensitive than visualization of the VBP in a blood smear, especially in those cases of low burden of VBP [11-14].

Hepatozoon canis and A. platys were the most frequently detected agents. Hepatozoon canis has been recently detected in dogs from Northeast India with a prevalence of $38 \%$ [15], slightly higher than the prevalence described here (31.43\%). These apicomplexan protozoans are transmitted by the ingestion of an infected tick [16]. The presence of ticks on dogs is sometimes used in practice as a predictor of some CVBD, especially in the lack of specific diagnostic tests. However, this study shows the lack of significant association between $H$. canis infection and detection of ticks in dogs during the physical exam $(P=0.34)$.

Sequencing confirmed that $31.43 \%$ of the dogs were positive to $A$. platys, and $27.14 \%$ to $E$. canis. Both rickettsial agents are transmitted by the same vector, Rhipicephalus sanguineus (sensu lato). As previously described for $H$. canis, tick infestation was detected in a high percentage of dogs infected by $A$. platys or E. canis $(63.63 \%$ and $68.42 \%$, respectively). Previous studies showed high prevalence of ectoparasite infestation in dogs from this area [2], and a recent review did show that a wide variety of tick species are parasites of dogs in Nepal [17].

Infections with Anaplasma spp. (1.34\%) and Ehrlichia spp. (10.66\%) have been recently detected in blood smears from hyperthermic dogs in Kathmandu [10]. The dogs infected with $E$. canis were older than the negative dogs in our study, probably due to a higher exposure to the vectors and their pathogens. Ehrlichia canis infection was more frequently detected in male dogs, although statistical test was non-significant $(P=0.08)$. This could be related to behavioural characteristics, as previously suggested [18].

Nepal is recognized as endemic for L. donovani [19]. However, the role of the dog as a reservoir in the cycle of this anthroponotic visceral leishmaniasis (AVL) (also known as kala-azar) and transmitted by Phlebotomus argentipes (anthropophilic vector) remains unknown. Some studies in India have hypothesized that dogs may constitute a reservoir for this species of Leishmania [20]. A previous study performed in the Terai region (southern Nepal) has shown that $P$. argentipes and $P$. papatasi with predilection to feed on humans or cattle, also feed on dog blood [8]. Phlebotomus papatasi has not been incriminated as a vector for $L$. donovani $[8,21]$. However, this sand fly is a reported vector for other Leishmania spp. ( $L$. major and L. infantum) in the Old World, suggesting that Nepal could become endemic for zoonotic leishmaniosis [22]. Our study shows a prevalence of $18.57 \%$ of Leishmania donovani complex in the tested stray dogs. There was no statistically significant correlation between Leishmania spp. detection and any signalment data, clinical findings, and environmental data. It was not possible to establish if these animals were suffering a clinical presentation of leishmaniosis or were just infected and carrying the pathogen at a low burden. The lack of compatible clinical signs and the low number of copies of parasite DNA detected, could support the second hypothesis. Thus, having confirmed the presence of Leishmania spp. by molecular tests, it would be interesting in the future to establish the role of the dog in the human leishmaniosis in Kathmandu.

Canine babesiosis has been recently reported in dogs from Kathmandu [9] and B. gibsoni constituted the most detected vector-borne agent found in dogs from Northeast India (43\% of the dogs positive to B. gibsoni and 3\% positive to B. vogeli) [15]. In contrast, in our study, prevalence was higher for B. vogeli $(12.86 \%)$, and lower for B. gibsoni (2.86\%). Babesia gibsoni has been widely described in Asia [15] and is transmitted by Haemaphysalis longicornis [23]. Other species of the genus Haemaphysalis have been previously detected in Nepal [17]. On the other hand, the main vectors described for $B$. vogeli are ticks from different genera (Dermacentor spp., Ixodes spp., and R. sanguineus (s.l.)) also found in dogs from Nepal [17]. The authors of the present study are cautious with the DNA sequences of Theileria spp. detected in dogs.

An unexpected finding from this study was the high rate of co-infections, detected in 29 out of 70 dogs 
(41.43\%). In agreement with this finding, another recent study in India has shown a high prevalence of dogs presenting co-infection by two or more agents $(44 / 130$, 34\%) [15]. The most common co-infection detected in our study was $H$. canis $+E$. canis. Canine hepatozoonosis and ehrlichiosis are both tick-borne diseases transmitted by $R$. sanguineus (s.l.). Some interactions between the pathogens and host cells in this co-infection have been previously suggested [24]. The high ratio of co-infections could be explained by the interactions of some of these pathogens when infecting dogs, as previously described [25].

There was no effect of BCS or sex on the prevalence of these VBP. The animals included in the study were stray dogs with difficulties to feed properly and most of them presented a low BCS. This could be related to the lack of statistical differences regardless of whether they present clinical signs. A previous study in Nepal detected that most of the dogs $(80 \% ; n=47)$ had an adequate BCS. However, ecto- and endoparasites were also detected in most of them $(83 \% ; n=49)$ [2].The lack of association between the presence of infection and the sex of the dogs in this study is consistent with other studies evaluating VBP in dogs from India $[15,26]$ and from Kathmandu Valley, Nepal $[9,10]$.

Clinical findings detected in the dogs included in the study were not directly related with the classical clinical picture of CVBD, and consisted mainly on wounds, myiasis, bone fractures, fungal skin lesions, and limb loss, among others. The lack of clinical signs in asymptomatic carriers, the co-infection with multiple VBP in the same animal or even the poor health condition in non-infected dogs constitute one of the barriers in the clinical diagnosis approach for these CVBD. In agreement with our work, a previous study performed in Chitwan District (central Nepal), also showed that there was a considerable number of apparently healthy dogs carrying haemoprotozoans and ectoparasites (49/59; 83\%) [2].

Future studies should focus on the evaluation of possible risk factors, as well as the presence of competent arthropod vectors to understand biological cycles of the parasites, the role of the dog as a possible reservoir in zoonosis transmission, and the control of these VBP affecting dog populations and, potentially, the human population.

\section{Conclusions}

To our knowledge, this study constitutes the first molecular report of VBP in stray dogs from Kathmandu, Nepal. Our results highlight the importance of several CVBD that should not be underestimated in the metropolitan area of Kathmandu. The prevention and treatment of these CVBD must be taken under consideration and implemented in the veterinary control in concurrence with population awareness programmes, animal birth control or rabies vaccination programmes. Further on this, considering the high detected prevalence of VBP and following the WSAVA vaccination recommendations, a check-up including ecto- and endoparasite control should be performed prior to vaccination in apparently healthy dogs that could be potentially infected. Further studies are needed to understand the role of the dogs and arthropod vectors in the transmission of these and other VBP in the metropolitan area of Kathmandu.

\section{Abbreviations}

BCS: body condition score; CRT: capillary refill time; CVBD: canine vector-borne disease; na: not applicable; rRNA: ribosomal ribonucleic acid; VBP: vectorborne pathogen.

\section{Acknowledgements}

The authors sincerely thank Professor Agustín Estrada-Peña for the support and the critical review of the manuscript. The authors also thank KAT Centre members for the opportunity to collaborate with this charity, especially all the volunteers who dedicate time and efforts to improve the health of the stray dogs of Kathmandu. Many of them collaborated in the sample collection for this study. We also thank Laura Altet and Lorena Serrano (VetGenomics, Bellaterra, Spain) for laboratory processing. Publication of this paper has been sponsored by Bayer Animal Health in the framework of the $15^{\text {th }}$ CVBD World Forum Symposium.

\section{Authors' contributions}

BA and BP collected the samples and data from the dogs. BA and DDR planned, designed the study, performed DNA extraction, analysed the data and wrote the manuscript. NF collaborated in DNA extraction. AV, FRF, MCG analyzed data and collaborated in writing the manuscript. AS planned, designed and supervised the study, analysed data and assisted in writing the manuscript. All authors read and approved the final manuscript.

Funding

Bayer Animal Health has sponsored the research included in the manuscript.

\section{Availability of data and materials}

All data generated or analysed during this study are included in this published article.

\section{Ethics approval and consent to participate}

Written and oral consent for patient enrolment was obtained for every case from owners or KAT (Kathmandu Animal Treatment) Centre responsible persons.

Consent for publication

Not applicable.

Competing interests

The authors declare that they have no competing interests.

\section{Author details}

${ }^{1}$ Department of Animal Medicine and Surgery, College of Veterinary Medicine, Complutense University of Madrid, Avda. Puerta de Hierro s/n, 28040 Madrid, Spain. ${ }^{2}$ Kathmandu Animal Treatment (KAT) Centre, Chapali Gaon, Budanilkantha, GPO Box 8975, EPC 4120 Kathmandu, Nepal. ${ }^{3}$ Department of Animal Pathology, Faculty of Veterinary Medicine, University of Zaragoza, Calle de Miguel Servet 177, 50013 Zaragoza, Spain. 
Received: 13 December 2019 Accepted: 1 April 2020

Published online: 21 April 2020

\section{References}

1. Kato M, Yamamoto H, Inukai Y, Kira S. Survey of the stray dog population and the health education program on the prevention of dog bites and dog-acquired infections: a comparative study in Nepal and Okayama Prefecture, Japan. Acta Med Okayama. 2003;57:261-6.

2. Massei G, Fooks A, Horton D, Callaby R, Sharma K, Dhakal I, et al. Freeroaming dogs in Nepal: demographics, health and public knowledge, attitudes and practices. Zoonoses Public Health. 2017:64:29-40.

3. Devleesschauwer B, Aryal A, Sharma BK, Ale A, Declercq A, Depraz S, et al. Epidemiology, impact and control of rabies in Nepal: a systematic review. PLoS Negl Trop Dis. 2016;10:e0004461.

4. Devleesschauwer B, Ale A, Torgerson P, Praet N, de Noordhout CM, Pandey BD, et al. The burden of parasitic zoonoses in Nepal: a systematic review. PLoS Negl Trop Dis. 2014;8:e2634.

5. Dhimal M, Ahrens B, Kuch U. Climate change and spatiotemporal distributions of vector-borne diseases in Nepal - a systematic synthesis of literature. PLOS ONE. 2015;10:e0129869.

6. Movilla R, Altet L, Serrano L, Tabar M-D, Roura X. Molecular detection of vector-borne pathogens in blood and splenic samples from dogs with splenic disease. Parasit Vectors. 2017;10:131.

7. Francino O, Altet L, Sanchez-Robert E, Rodriguez A, Solano-Gallego L, Alberola J, et al. Advantages of real-time PCR assay for diagnosis and monitoring of canine leishmaniosis. Vet Parasitol. 2006;137:214-21.

8. Burniston I, Roy L, Picado A, Das M, Rijal S, Rogers M, et al. Development of an enzyme-linked immunosorbent assay to identify host-feeding preferences of Phlebotomus species (Diptera: Psychodidae) in endemic foci of visceral leishmaniasis in Nepal. J Med Entomol. 2010;47:902-6.

9. Phuyal S, Jha V, Subedi M. Prevalence of blood parasites in dogs of Kathmandu Valley. Nepalese Vet J. 2017;34:107-12.

10. Bhatta T, Acharya N, Acharya KP, Thapa BR. Prevalence of blood parasites in hyperthermic dogs of Kathmandu valley, Nepal. Asian J Anim Vet Adv. 2018;13:67-72.

11. Solano-Gallego L, Miró G, Koutinas A, Cardoso L, Pennisi MG, Ferrer L, et al. LeishVet guidelines for the practical management of canine leishmaniosis. Parasit Vectors. 2011:4:86.

12. Sainz Á, Roura X, Miró G, Estrada-Peña A, Kohn B, Harrus S, et al. Guideline for veterinary practitioners on canine ehrlichiosis and anaplasmosis in Europe. Parasit Vectors. 2015;8:75.

13. Solano-Gallego L, Sainz Á, Roura X, Estrada-Peña A, Miró G. A review of canine babesiosis: the European perspective. Parasit Vectors. 2016;9:336.
14. Otranto D, Dantas-Torres F, Weigl S, Latrofa MS, Stanneck D, Decaprariis D, et al. Diagnosis of Hepatozoon canis in young dogs by cytology and PCR. Parasit Vectors. 2011;4:55

15. Sarma K, Nachum-Biala Y, Kumar M, Baneth G. Molecular investigation of vector-borne parasitic infections in dogs in Northeast India. Parasit Vectors. 2019;12:122.

16. Baneth G, Samish M, Shkap V. Life cycle of Hepatozoon canis (Apicomplexa: Adeleorina: Hepatozoidae) in the tick Rhipicephalus sanguineus and domestic dog (Canis familiaris). J Parasitol. 2007;93:283-99.

17. Pun SK, Guglielmone AA, Tarragona EL, Nava S, Maharjan M. Ticks (Acari: Ixodidae) of Nepal: first record of Amblyomma varanense (Supino), with an update of species list. Ticks Tick Borne Dis. 2018;9:526-34.

18. Costa LM Jr, Rembeck K, Ribeiro MFB, Beelitz P, Pfister K, Passos LMF. Seroprevalence and risk indicators for canine ehrlichiosis in three rural areas of Brazil. Vet J. 2007;174:673-6.

19. Stauch A, Sarkar RR, Picado A, Ostyn B, Sundar S, Rijal S, et al. Visceral leishmaniasis in the Indian subcontinent: modelling epidemiology and control. PLoS Negl Trop Di. 2011;5:e1405.

20. Jambulingam P, Kumar NP, Nandakumar S, Paily K, Srinivasan R. Domestic dogs as reservoir hosts for Leishmania donovani in the southernmost Western Ghats in India. Acta Trop. 2017;171:64-7.

21. Pandey K, Pant S, Kanbara H, Shuaibu MN, Mallik AK, Pandey BD, et al. Molecular detection of Leishmania parasites from whole bodies of sandflies collected in Nepal. Parasitol Res. 2008;103:293-7.

22. Schwarz D, Andrews J, Gauchan B. Visceral leishmaniasis in far western Nepal: another case and concerns about a new area of endemicity. Am J Trop Med Hyg. 2011;84:508.

23. Higuchi S, Simomura S, Yoshida H, Hoshi F, Kawamura S, Yasuda Y. Development of Babesia gibsoni in the hemolymph of the vector tick, Haemaphysalis longicornis. J Vet Med Sci. 1991;53:491-3.

24. Baneth G, Harrus S, Gal A, Aroch I. Canine vector-borne co-infections: Ehrlichia canis and Hepatozoon canis in the same host monocytes. Vet Parasitol. 2015;208:30-4.

25. Baxarias M, Álvarez-Fernández A, Martínez-Orellana P, Montserrat-Sangrà $S$, Ordeix L, Rojas $A$, et al. Does co-infection with vector-borne pathogens play a role in clinical canine leishmaniosis? Parasit Vectors. 2018;11:135.

26. Rani PAMA, Irwin PJ, Coleman GT, Gatne M, Traub RJ. A survey of canine tick-borne diseases in India. Parasit Vectors. 2011:4:141.

\section{Publisher's Note}

Springer Nature remains neutral with regard to jurisdictional claims in published maps and institutional affiliations.
Ready to submit your research? Choose BMC and benefit from:

- fast, convenient online submission

- thorough peer review by experienced researchers in your field

- rapid publication on acceptance

- support for research data, including large and complex data types

- gold Open Access which fosters wider collaboration and increased citations

- maximum visibility for your research: over $100 \mathrm{M}$ website views per year

At BMC, research is always in progress.

Learn more biomedcentral.com/submissions 